\title{
Delivering the message: a theoretical study on designing science content for nature-based experiences
}

\author{
Sanha Kim
}

\begin{abstract}
The urgent state of our global environment calls for collective action, which depends in large part on effective science communication for better understanding and awareness. Activities and institutions that provide opportunities to learn about nature all ultimately rely on scientific findings about nature. Although science produces the knowledge and information about nature, for the content to be accessible and meaningful to the general public, it needs to be processed by what I call science content design. This process is similar to the concepts of interpretation in tourism, or aesthetic understanding in alternative science education. This study is a theoretical exploration on the definition and nature of science content design, what constitutes its process, and how the content can be designed. Focusing on the fields of macro-biology, I also discuss the types of biological content generally used in nature-based experiences, and examine model cases of biological content design.
\end{abstract}

KEYWORDS: Science content, design, nature-based experiences

\section{Objective}

What is the common subject matter in zoos, museums, wildlife tourism, or any other type of nature-based activity? The underlying principles and mechanisms of biological phenomena, and the diverse relationships and variations among living creatures constitute the substance of experiencing nature. In short, the content of how nature works presented in a certain way is what is 'consumed'. Science provides the raw material, but other skills and approaches are called in to make it more palatable for the general public. The underlying process common to these applied activities is the process of science content design. The objective is to theoretically explore the meaning, function, and practice of science content design. First, I examine the context and definition of biological content. Second, I discuss what kind of biological content is utilized and how it is processed. Third, I analyze various design techniques and apply them to real world examples.

\section{Context}

Environmental degradation and loss of biodiversity have become a recurrent theme in the modern world despite the best effort of countless endeavors to mitigate the impact caused by human activity. News of climate change and imminent species extinction abound in 
the media but still fails to attract the sufficient amount of attention and support it desperately needs. Although overall awareness is growing, urgent conservation messages frequently find themselves perceived as irrelevant, repetitive, and even boring. Science alone will simply not do the job. Providing people with interesting, enjoyable, and compelling stimuli about the natural world, as opposed to mere factual information, is critical in bringing desirable changes in attitude and behavior [1]. The same applies to any type of nature-based activity where the goal of balancing environmental integrity and human needs hinges on inducing the latter to agree with, or even demand, the former [2]. Real communication and persuasion has to be achieved.

For many people nature, or more specifically wildlife, is already a major source of attraction as evidenced in the sharp rise of demand for recreation or entertainment in nature or through nature-themed services [3]. Museums, zoos and aquariums, nature parks and reserves etc., all strive to offer programs that aim to enrich and enliven the visitor's experience. Such activities usually include a significant element of education that urge the participant to engage with the subject at hand both intellectually and emotionally. Research shows that visitors generally enjoy and value this aspect of the nature experience, and view learning and discovery as an integral part of the entertainment [4-6]. Thus, the perceived lack of responsiveness towards some environmental issues may be due to an inability to capitalize on an existing potential. Harnessing one's interest, motivation, and receptivity while delivering sound information is vital in making an individual more appreciative and understanding of the natural world and its value.

\section{Presenting the natural world}

To exploit the inspirational powers of the natural world we need to begin with the science that concerns it. Everything we experientially derive from nature will ultimately depend on and be limited by what we know about it. Biology is usually bestowed as the relevant academic field or reference base to the content of many nature-based activities. For practical purposes of this study, we limit the notion of science to biology, focusing on the so-called macro-biology fields such as behavior, ecology, or evolutionary biology. It is the type of wildlife or organism-oriented experiences of nature concerned with macrobiology, by large, that are the most popular and accessible. The subject matter of this area of biology is distinct from other scientific disciplines in that it has direct public appeal. Animals, plants, and their diverse interactions are used widely as characters, motifs, and objects, in all forms of communicative media. Nonetheless, familiarity itself does not foster scientific understanding or convey biological content. Indeed familiarity can also pose difficulties when it strengthens stereotypes or preconceptions. The delivering of knowledge requires some sort of 'processing' and 'presentation' in order to fulfill its goal.

The need of stimulating interest while educating about nature has long been recognized in the wildlife tourism research literature centering on the concept of 'interpretation'. Interpretation is the process of communication that helps people make sense of, understand, and appreciate the significance of a place, object, or phenomena [7, 8]. The term was first 
defined in this sense by Tilden (1977) as "an educational activity which aims to reveal meanings and relationships through the use of original objects, by first hand experience, and by illustrative media, rather than simply to communicate factual information" [9]. It also refers to the skills, practice or profession of the educational process or enlightenment experience [10], and aims to 'open the minds of people' so they are receptive to the world's signals [11]. The effectiveness of the communication, and not only the process itself, is a major concern of interpretation as can seen in cases where environmental interpretation is widely used as a visitor management strategy to reduce negative impacts $[4,12,13]$. Interpretation can be performed via static media such as signs, information panels, brochures, as well as through more dynamic forms such as guided tours, interactive displays and exhibitions. The common meaning of the word 'interpretation', as in translating one language into another, is also an apt analogy to the concept in the sense that interpretation turns technical or professional scientific information into comprehensible or 'digestible' material.

Similar concepts appear in the education literature in the form of 'aesthetic understanding', which advocates the role that aesthetic experience plays in science learning. Under this view, science learning is best achieved as an integrated act that allows blending of cognitive and discursive understanding with affective and artistic ways-of-knowing [14]. This perspective draws heavily from Dewey's ideas on aesthetic theory and the significance of experience in the learning context. Dewey (1934) asserted that an aesthetic experience occurs when "the material experienced runs its course to fulfillment [15]. Only then is it integrated within and demarcated in the general stream of experience from other experiences." As summarized by Girod \& Wong (2002), it is a "negotiated process between action and undergoing that ends in expanded perception" [16]. This kind of experience is transformative, unifying, compelling and dramatic in its quality and allows the experiencing individual to rearrange and reconstruct one's own perception and value about the world [17, 18]. In short, one's relationship with the world is transformed [19]. When applied to science education, it brings out an understanding of content and empowerment of scientific thinking at the same time [14]. Here, the teaching of science is actively seeking a merger with the arts to produce an emotionally charged experience by which the educative goals are attained [20]. Techniques related to the artistic crafting of science education are recommended as practical methodology and have been put to test with students for empirical evaluation of this learning model $[16,21]$.

\section{Approaching biological knowledge as content}

\subsection{Informed aesthetics of nature}

Undertaking the task of making the natural world more appealing to the masses is in part a response to current environmental urgency, but an artistic take on biological findings is by no means novel, nor a forced makeover for marketing an otherwise unaesthetic field. Ranging from simple depictions of fauna and flora to intricate experimental inter- 
playing between the arts and sciences, biological phenomena and principles have always been a constant theme of creative works. Ernst Haeckel's early drawings of radiolarians that combine scientific observation and visual artistry may be the best-known example of artwork by a biologist [22], but numerous other works by scientists and artists, or hybrids of both professions, showcase the myriad ways biological themes can be explored artistically [23, 24]. The aesthetics so readily evoked when experiencing living forms prompted the eminent biologist E.O. Wilson (1984) to coin the term 'biophilia' which claims that we possess an innate tendency to focus on life and lifelike processes, of which aesthetic pleasure and emotional enticement towards nature is the central issue [25, 26]. The term aesthetic here, and throughout this paper, is not restricted to a type of valuation perspective on nature [27] but refers more widely to any sensual emotional, spiritual dimension associated with experiencing nature. With the capacity to be interested, thrilled, and moved by nature, we can appreciate the wild via the 'aesthetic route', a path guided by our aesthetic sensitivity but also enhanced by a greater cognitive understanding [28]. When an aesthetic experience of nature is enriched with intellectual advancement, or vice versa, the result is invariably synergistic. The combination, or merging, between scientific content and artistic interpretation is potent and popular but surprisingly understudied in terms of what are the properties of biological content, how is it processed, and which factors are relevant.

\subsection{The nature of biological content}

Content is commonly defined as "the matter dealt with in a field of study" or more simply "something contained" [29]. In the present context, biological content are the observations, measurements, recordings, analyses, explanations, statements, models and other representations of life in nature in the field of biology. Accounts of content are generally given in the context of communication, where content is the 'message' in the signal that is exchanged. Traditional communication theory, however, concerns itself more with quantitatively explaining the transfer of information and the form in which content is embodied rather than the nature of content itself $[30,31]$. The notion of information content relevant to this study is in the ordinary, semantic sense of the word which refers to what is contained in the signal, the form assumed by information content, but not limited to as content also depends on the receiver's detecting and extracting abilities. Any part of an information comprises its content but does not necessarily dictate what exactly is the content, and information can greatly exceed the conventional meaning of a signal according to how able the recipient is at 'reading the signs' [31]. Thus, content should be conceptually distinguished from meaning as well as terms such as value or knowledge. While there may be, say, value embedded as content it does not naturally follow that the value will be conveyed upon receiving the signal. Although content is reliant and checked by the physical features of the signal, it is not strictly determined and can expand or transform when subjected to appropriate 'exploitation'. This somewhat relative nature of content is reflected in Ackoff's (1989) system of hierarchy, which classifies content into data, infor- 
mation, knowledge, understanding and wisdom (information here is used in the narrow sense, as opposed to information theory) [32]. Through an increasing level of organizational and relational processing, raw and meaningless data are gradually elevated to higher forms of content, ultimately reaching the status of wisdom.

Biological content is no exception to this principle. Science content of nature arises from generating fragmentary data, exposing the information to systematical and critical evaluation, and confirming or rejecting hypotheses and theories. As with content in general, a skillful interpreter will more efficiently glean content from a given piece of biological information, which in many cases will be a biologist. However, skill in recognizing content does not solely rely on academic expertise. The realized potentiality of content will also depend on the ability to make aesthetic sense on part of the observer. A typical behavior of an animal may not appear noteworthy to the seasoned scientist, but nonetheless may prove to be inspiring when identified and elegantly coupled with cultural significance or sentiment. This does not mean biology should be open to amendment by the arts as a science, but does suggest that the aesthetic view is as important as the scientific view when utilizing biology as a content source for designing experiences of wildlife and nature.

Another reason why an aesthetic approach is important is due to the intimate relationship between content and form. Content cannot exist but in some form or other, but as in Hegelian aesthetics, it is the particular relationship between content and form that defines the manifestations of art forms [33]. How well an idea is combined with a mode of expression in varying degrees, or the appropriateness of a thing's content and form to each other is the criteria of aesthetic quality [34]. Such judgments of quality apply equally to forms containing biological content that are designed to communicate sciencebased ideas of nature. In the case of biological content, the question is not whether a work is good art or not, but whether the interesting points of scientific significance has been appropriately paired with the right method of presentation so that the appeal is captured'. By approaching biological content from an aesthetic perspective it is able to exercise such judgment on quality, as content is not causally ascribed to form [34]. This notion of combination may have the effect of creating a clear-cut distinction and operational relationship between content and form. To the contrary, although conceptually distinguished, "content is not only what is presented but also how it is presented, and in what context" [35]. Additionally, the advent of new media with multimodal interfaces further challenges the traditional concept of content. Modern interfaces not only display content but also shape how content is perceived and experienced by the user. Interactive systems used frequently nowadays in nature-based experiences are designed for a certain way of sensing in a certain kind of environment, and "by presenting information in a specific manner or medium, the interface designer defines the way this interface shapes this point-of-view" [36]. To the extent content depends on our ability to make sense of it, the interface of the content experience also constitutes content. Thus, being the creator of biological content entails assuming the role of the interface and presentation designer, as well as being the producer of biological knowledge. 
Furthermore, it is often the case that people make sense of biological content through social interaction, which creates yet another dimension for design. Visitor research has shown that dialogue and questioning are critical tools for exploring and understanding scientific content in exhibit settings [37, 38]. Group experience is the norm for most kinds of biological content, so the kind of social engagement that take place can directly impact learning and interpreting [39]. Without taking into account of the socio-cultural perspective, even a well designed content may fail to register.

\section{Science content design}

Nature-based activity relies on content derived from what we know about nature. Science is the primary producer of data, information, and knowledge about nature. Science content, including the form it is contained in, is brought about through design. What then, is science content design? It is the process of applying design thinking and technique to the content of science, in our case biology, to render the content compatible with the medium that embodies it and maximize the purported effect of the activity utilizing the content. Design here is not used in the traditional sense as the conception of visual form [40], but in the more encompassing meaning as the thought and making of objects, communication, organized activities, complex systems and environments [41]. Although the practice of science content design is prevalent in any kind of nature-based activity, the act of processing information to yield content appears to be performed almost automatically or unnoticed by its practitioners. Even less recognized is the role of science itself in shaping content and its presentation. Typically, the designer is called in to work on 'untreated' scientific material after the organizer decides on the theme and scope of the nature-based activity. It is a unidirectional approach of applying design as a late polishing step, rather than incorporating design principles from the beginning of content sourcing. As discussed previously with regard to the nature of content, the amount of meaningful or useful content derivable in a given amount of information depends heavily on the capacity of the user. Thus, the more dimensions the observer is aware of the more content can be developed or 'discovered'. The science content design approach allows the content to be generated from both the scientific and artistic perspectives so that the strength and sensitivities of both viewpoints are functional and interactive with each other.

As depicted in Figure 1, I propose a process of designing science content. First, the theme or subject of the intended content is selected. This first step is to adjust the focus of the content so that its takeaway message is clearly resolved. Selection need not pinpoint to a single factual statement; the totality of the necessary information should be the unit of selection. Second, the boundary or scope of the selected theme is demarcated. Knowledge is endlessly embedded in and linked to other knowledge, and by demarcating the extent of the content an operational frame is set. Third, research results about the subject are reviewed and interpreted to reach various levels of generalization. In reality, any research topic is constantly subject to ongoing debate and refutation. Without smoothing out the lines of the academic landscape to some degree, the state of the knowledge 


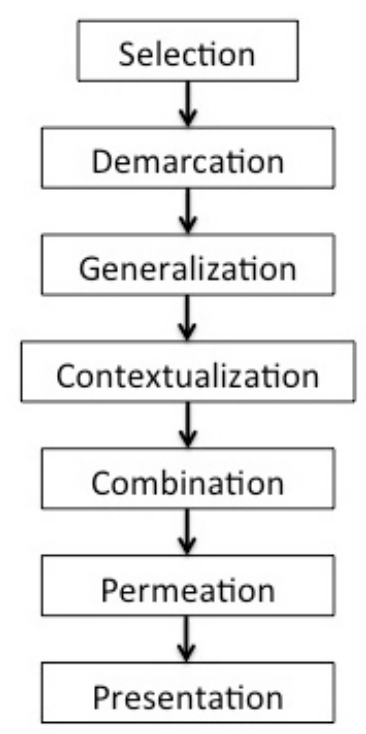

Figure 1. The proposed process of science content design.

may be too coarse to be later presented in any way. Judgment skills for attaining a delicate balance between scientific objectivity and semantic narrative are critical. Fourth, the finely defined piece of content is imbued with an appropriate context. Context can be any kind of environment or setting that works as a physical or mental backdrop, including the socio-cultural matrix, to which the content is viewed against. It provides the necessary particulars and perspectives to 'make sense' of a given science content. Fifth, the content is coupled with and expressed through a medium to be materialized. The delivering of content through media should be carefully conducted so that the content's idea and appeal are captured in the best way possible. Sixth, the information elements and aesthetic elements should be allowed to mix and permeate each other. This is effectively the most interactive stage where artistic qualities influence the shaping of science content, and vice versa, to result in a chemical fusion with added value. Seventh, the fully materialized content is adapted for presentation or performance. The potential audience or end-user of the purported program should be kept in mind to take into account the interest factor so critical in nature-based activities. To encapsulate, the whole process of science content design can be thought of synergistically bringing together scientific rigor and aesthetic sensibility without compromising the merits of the respective fields.

The importance of content and the way it is presented is constantly emphasized in science education or ecotourism research, yet studies that deal with how to actually design science content remain scarce [42]. For instance, presenting information using a theme is highly effective for interpretation $[4,13,43]$ as is well known in the wildlife tourism literature, but it is not clear how to develop a theme taking advantage of the information resource base and make it aesthetically effective at the same time. As Ham \& Krumpe (1996) note, "communication that develops a theme advocates a belief" [44] thus the- 
matic interpretation should be inspired from the science that forms the knowledge basis. However, this is not to say that themes should be strictly scientifically defined, but that by consulting the design approach to science content one can create themes that tap into the aesthetical resources of science. Although this aesthetic side of creating and presenting science content is crucial in creating effective nature experience, it is still considered separate from the science content itself or even subordinate to it [45]. This presents a deep misunderstanding of the nature of science and an enormous lost opportunity for producing high-quality science content. Enhanced learning and positive conservation attitudes through nature-based activities result from a state of mindfulness of the participant, which is induced by characteristics and structure of the content [46]. Furthermore, aesthetic elements of the medium that presents science content can affect how the recipient accepts and understands the science itself [47].

\section{Practical biological content design}

\subsection{Design techniques for biological content}

Nature-based activities such as zoos, aquariums, museums, wildlife tours, science classes, field trips, and exhibitions all use and depend on science content from the field of biology to a certain degree. What kind of biological content is utilized and consumed in these activities? Commonly used biological content can be summed up in a few categories (Table 1).

For example, a typical museum specimen display tends to present structural or systematic content focusing more on anatomical features of an animal, while a typical wildlife tour will tend to offer taxonomic content concentrating on the features or habits of a sighted species. This grouping of content shows that the broad types of biological knowledge may not be as diverse as one might expect. Of course, the particulars of biological content for nature-based activities would be infinite, but whatever the subject, the information typology itself does not boast a range wide enough for biological content design to simply make use of what is available. In fact, it is this repetitious nature of information type that, when offered without it being well processed or designed, can cause a diminish in interest of the content. Visitors to zoos see numerous panels that differ little in the type of information given, say, on the animal's habitat, and thus after a few readings may merely remember that 'animals live somewhere'. The relationship between an animal and its habitat is a rich source of fascinating information but unfortunately is not exploited at all in this hypothetical case. Nature experiences rely heavily on interesting biological content that can capture the attention of an audience rather than factual or raw information $[2,42]$. The biological content needs to be effectively designed, or interpreted, and yet be scientifically sound at the same time.

In what ways, then, is biological content designed? Several design techniques or guidelines can be applied throughout the design process of science content (Image 1). Pierssené (1999) provides some techniques useful for designing content in the aptly named chapter 


\begin{tabular}{|l|l|}
\hline Content type & Description \\
\hline Structural & $\begin{array}{l}\text { Structure or constituent elements of biological entities such as cell, tissue, } \\
\text { organ, organism, population or community }\end{array}$ \\
\hline Relational & $\begin{array}{l}\text { Inter-individual or species relationships such as competition, predation, } \\
\text { cooperation, commensalism, parasitism, etc. }\end{array}$ \\
\hline Systematic & $\begin{array}{l}\text { Functional aspects or mechanisms of natural systems such as organ sys- } \\
\text { tems, mating systems, ecosystems, etc. }\end{array}$ \\
\hline Historical & $\begin{array}{l}\text { Evolutionary or historical accounts of lineages, adaptations, speciation, } \\
\text { extinction, etc. }\end{array}$ \\
\hline Comparative & $\begin{array}{l}\text { Physical configuration or distinct appearances of body, bodily parts, or } \\
\text { extended phenotypes }\end{array}$ \\
\hline Geographical & $\begin{array}{l}\text { Anterpreting different size, scale, and other abilities based on comparison } \\
\text { between individuals or species } \\
\text { or unique habitat characteristics }\end{array}$ \\
\hline Taxonomic & $\begin{array}{l}\text { Detailed information of natural history, behavior, and ecology unique to } \\
\text { distinct taxonomic groups }\end{array}$ \\
\hline Situational & Plight or conservation status of biological entities \\
\hline Methodological & Scientific methods used to study and analyze living forms and systems \\
\hline
\end{tabular}

Table 1. The major types of biological content used in nature based activities.

"Frog into prince: turning information into interpretation" in his book on environmental interpretation [10]. Effective interpretation focuses more on the how and why something occurs rather than the mere what and when of events, it utilizes a theme that implies selection of that particular theme and a rejection of alternatives, and employs various hooks such as curiosity, movement, humanity, involvement, shock, superlatives, gadgetry, and novelty [10]. Analogies or metaphors are also powerful tools to present content in a new light and influence the nature of the recipient's understanding [16, 48]. In the case of nature tourism, it is important that emphasis is placed on relationships between organisms rather than concentrating on species identification [49], and to "present a whole rather than a part" [4]. Using the surprise factor or conflicts are also useful techniques [46]. Artistically representing science itself can be viewed as a design technique that offers multi-sensory ways of processing content [50].

A crucial approach in designing biological content is to apply aesthetic critique. What I mean by aesthetic critique is the act of capturing the essence or salient features of a content and articulating how a given content can or should be appreciated [51]. Rolston (1987) offers an excellent example of this aesthetics of nature, focusing on the experience of wildlife. For instance, the fact that it is difficult to see a wild animal is given significance because this "probability, improbability, and contingency" are precisely what makes the experience genuine [28]. The fleeing response of wild animals are interesting on their own because it shows they "are subjects... the aesthetic experience differs because of reciprocity... wildlife have, so to speak, points of view" [28]. Even the pres- 
ence itself of an adult animal signifies the developmental success of that individual and its strive towards an adaptive ideal of that species, which constitutes a "coupling of aesthetics with genetics and evolutionary ecology" [52]. Aesthetical critique such as the above can transform the ways wildlife is experienced because it offers novel perspectives to appreciate natural phenomena such as distribution or adulthood in animals. We can simply state factual information about an animal's behavior only to confine its significance to just that, mere facts. As such critique concentrates on the essence of content and reaches deep inside to make sense of what the content is truly about, it is more important than general design techniques that focus more on making the content attractive or entertaining.

In a similar fashion, I propose several principles of designing biological content that help strengthen the meaning or significance of the information while enhancing its interest value. Of course, the following is by no means an exhaustive list of design techniques that can be used, but simply serve as guidance to how content can be developed. I also point out that the techniques are content-centered and do not cover user-social dimensions as it exceeds the scope of this study.

Extraction: identifying the core message of a body of knowledge and presenting it in a purified form. Predation plays a role in maintaining species diversity as evidenced in Paine's (1966) classic study of coastal rock pools. The presence of the starfish, the top predator in this ecosystem, determined whether the number of any one species becomes dominant over others [53]. Although the study clearly shows the connection between predation pressure and the species composition, it is necessary to single out this 'positive side' of predation that runs counter to its generally negative conceptions and point out that the effect of a predatory act is not limited to nourishing the predator but also reaches further by affecting the ecological community.

Composition: composing the critical components of content in a way that maximizes the structural coherency and thus its semantic impact. In some cases, succinct summarizing of a study can reduce its interesting dimensions, which may aid in grasping the significance of the research. Seyfarth and Cheney's (1980) study on the alarm calls of vervet monkeys showed how different types of predators elicit different types of acoustic signals and subsequent behavior [54]. Rather than presenting the information in such a compressed form, it is far more effective to match each predator to each avoidance behavior, and also to combine the additional findings of mistaken calls made by juvenile individuals and their ontogeny to solidify the findings as a whole. The same applies to showing the 'step-by-step' nature of education in the teaching behavior of meerkats [55], or the hammer-and-anvil coordination of tool using chimpanzees to crack open nuts [56].

Illustration: visually demonstrating the temporal procedure or spatial configuration cogent to a phenomenon to spell out compressed stages or effects. To make sense of events resulting from diachronic or accumulative processes, it is helpful to illustrate a portion of the actual actions involved, both literally and figuratively. The peacock's tail is a classic example of sexual selection but the explanation is hardly impressive when given verbally 
as an abstract principle. By 'showing' the numerous phenotypes and selective acts made over generations, and the gradual effects of such choices in a population, one can be made to 'see' sexual selection at work. Of course, the effectiveness of this method would depend on how appropriate the selected portion is out of the whole process. Spatially illustrating habitat fragmentation would be helpful in the same manner to understand its effects on population dynamics and biodiversity.

Framework: assigning a physical or conceptual frame to phenomena that provides points of reference relevant in positioning and evaluating the information. To the untrained eye, the vast majority of scientific knowledge is too fragmentary or arbitrary to apply any kind of value or criteria. A quantitative measurement becomes relevant only when considered among a meaningful range of other values. I studied the feeding behavior of wild gibbons focusing on the variation over time in consumption of different parts of their food plants [57]. Although the time spent by gibbons feeding on fruits, flowers, and leaves are valuable in their own right, the numbers attain informative value when compared to other gibbons in different habitats [58] or viewed under the environmental context where that feeding behavior occurs. For example, when one realizes that the feeding happens in a confined territory and the resource base cannot be expanded, or that feeding must cope with changes in extremely local food plant phenology, then simple information such as feeding time can become interesting.

Implication: interpreting what is or can be implied in biological phenomena to address the relevant relationships, mechanisms, or principles at work. Knowledge is often presented in the form consisting of visible phenomena and a causal reaction underlying it. For that reason, the visible forms are thought separately from the forces that shape them, and thus the merit of their explanations are not fully reflected when trying to interpret those forms. Pointing out what is implicit in a phenotype can help bring forth abstract relationships as real, engaging manifestations of the natural world. It is a common fact that camouflage reflects the environment of the animal that possesses it. But to read the habitat from the camouflage rather than vice versa, and pointing out that the camouflage of, say, a clouded leopard embodies the light scattering patterns through rainforest vegetation, presents the relationship between habitat and body markings in a whole new light.

Emphasis: accentuating the outstanding features or characteristics of phenomena to promote appreciation of the subject. In certain cases, not just the facts of the information per se, but the quantitative or qualitative degree of an information's aspect is critical in understanding the significance of the phenomena. The unlikeliness or difficulty of a evolutionary pathway, the fragility of an ecosystem, the degree of specialization of deep sea creatures, the complexity of food webs can be highlighted and emphasized over the details of the subject, which can function as a mental 'anchoring point' to organize the information concerned.

Narrative: applying a structure in the form of a story to the content to strengthen its structure and assist comprehension. Animals and plants can be easily given roles in sto- 
ries that contain and convey scientific knowledge, but even inanimate objects such as rocks can be used in a narrative structure to enhance the results of scientific learning [14]. When the content is designed into a story, it need not retain all the elements of typical fiction; introduction, development, turn and conclusion. As long as the content is unfolded through a thematic and narrative flow, the story, albeit partially constructed, will be recognizable and effective. Stories have additional value because they elicit value orientations [59], which are useful in designing biological content related with emotions and priorities, such as conservation.

\subsection{Cases of biological content design}

In the real world, biological content has to be presented in some kind of physical form. Verbal explanation by a guide or instructor is a common and effective way to convey knowledge, and its content can be carefully designed just like with any other communicative media. Effective speech, however, is also a trait closely linked to individual talent and personality which may not be applicable generally. In order to make explicit the content and how they are processed, I have chosen a few examples of biological content design in forms of exhibitions or visiting facilities in the United Kingdom that cover a variety of nature experiences. I have given detailed accounts of each case and the points cogent to analyzing them from a content design perspective.

\section{The Cocoon, Museum of Natural History, London}

Built as an expansion to the renowned Natural History Museum in London, this facility makes direct use of science research itself as its main exhibit by tapping into the institute's resources it is based on. Openly claiming to "blur the boundaries between the public galleries and behind-the-scenes science", the centre brings forth biologists and their research world to the display window who guide visitors to get hands-on experience in various fields such as invertebrate taxonomy or tropical botany. Here, the fact that actual scientists, perhaps residing at that very moment in the adjoining building, present biology from a personal perspective is the critical framework. This engages the viewer in a way very different from exhibits that rely on non-personal narratives and allows the viewer to identify her/himself with that expert, and thus also with the subject matter. The field trip section at the end of the tour is the best example of science content design in the facility, in the sense that it employs various design techniques successfully. For example, the viewer can place her/himself in the shoes of a tropical botanist to organize a field trip to collect plant specimens. Starting from paperwork such as obtaining research permits, you are instructed to go through all the necessary steps as a real biologist would have to in preparing for such an expedition, and through this learn about what and how tropical plants are studied. The stage of preparation is singled out from the entire research process and emphasized because it highlights the various aspects involved in professional research. Components related to taking care of administration and checking appliances 


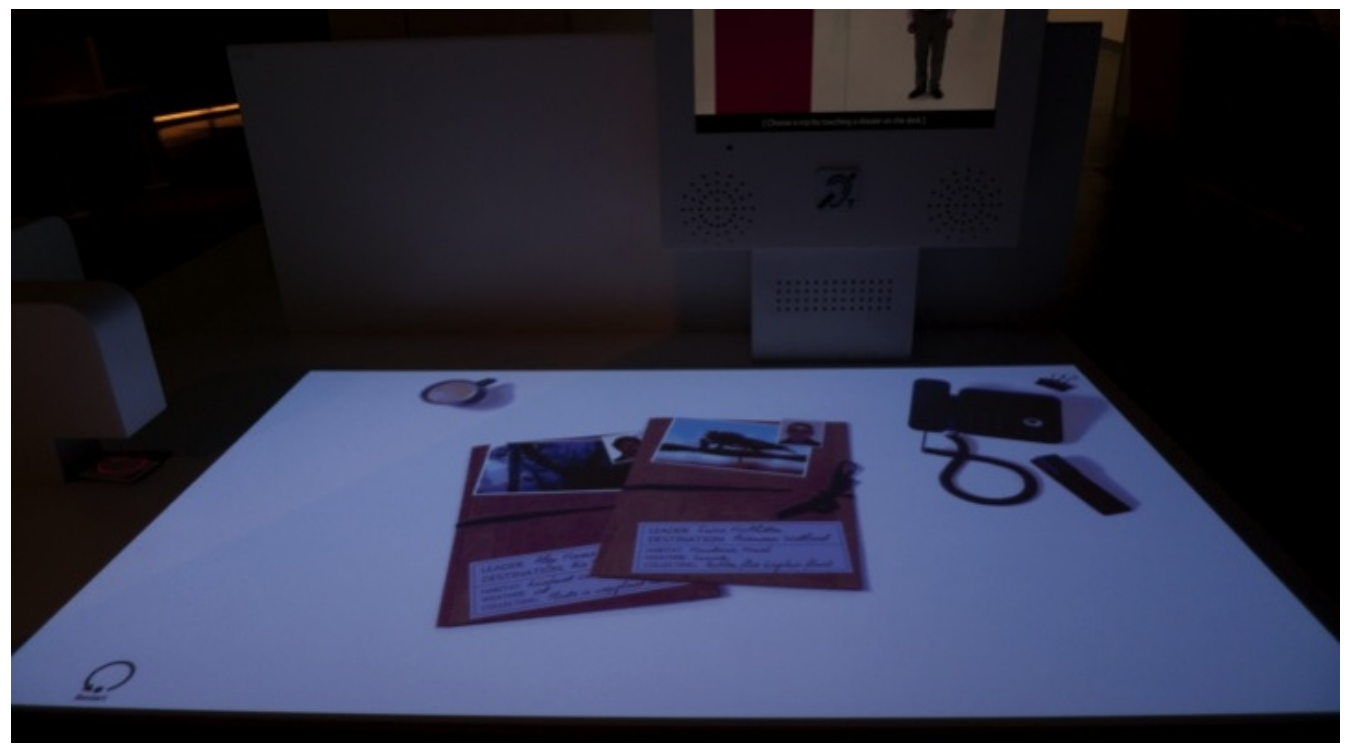

Figure 2. The interactive virtual desk of the field trip experience in the Cocoon, Natural History Museum in London.

are selected and composed to render an organized picture of the actual activity. These features are projected on a virtual desk of a biologist where letters are opened, calls answered and bags are packed, which vividly illustrate the physical reality of field science and enhances its presentation value (Figure 2). To promote involvement, choices are given to the participant throughout the tour, such as what clipping tools to bring for cutting up samples. Each choice has its consequence as demonstrated at the end, which reveals its significance in light of the purpose and condition of the fieldwork that is described.

\section{WWT Wetland Centre, London}

For outdoor centers that depend on free moving wildlife, it is somewhat difficult to provide well-designed scientific content. Not only because the animals themselves are the focus of the visitor's experience rather than the knowledge about them, but also because designing content usually implies a degree of control over its material. The Wetland Centre of WWT, London, offers an example of utilizing the dynamic coming and goings of waterfowl as their main content in the observatory tower, by applying an analogy between migratory birds and commercial air travel. Shown on the wall are 'flight information' for various wetlands across Europe, while the deck looks out onto the main watershed in the reserve. Even though it is very unlikely for a visitor to catch the exact moment of a bird's arrival, the airport context primes the observer to 'read' the significance of migration, and the importance of the center itself. In an interactive panel at the deck birds are given passports, complete with name, origin, and occupation, that further convey information about the species (Figure 3). It is a classic example of a themed interpretation of wildlife phenomena based on analogy to design the biological content of interest. 


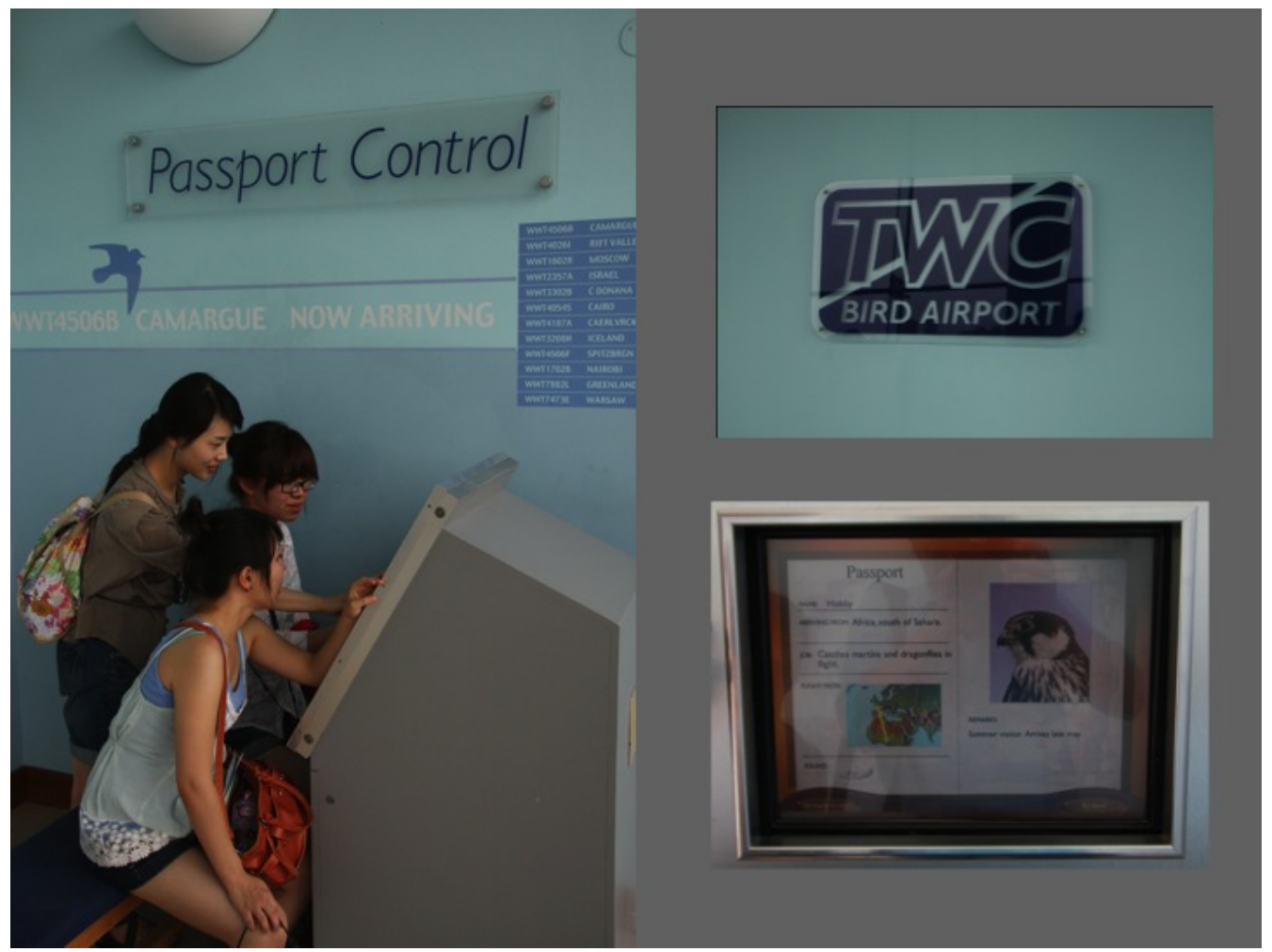

Figure 3. The airport-themed observatory tower and information panel of the WWT Wetland Centre in London.

\section{Conclusion}

Knowledge about the natural world is the essential subject matter of all nature-based activities, but if it is simply given without the content and presentation being designed appropriately, the information may fail to make an intellectual or emotional impact, or even be paid any attention at all. While scientific research produces the knowledge itself, I suggest that the content should be viewed from an aesthetic perspective and be subjected to various design techniques without compromising its scientific validity, if it is to be efficiently conveyed to the wider public. I have proposed some ways of approaching and applying science content design focusing on macro-biological disciplines that are among the most popular and accessible fields in science, which are also critically important in promoting public awareness to address pressing environmental issues. Current design of exhibits or experiences can benefit by adopting the science content design perspective for the entire development process to maximize the fusion between the arts and sciences. Future research may be aimed to establish a balanced relationship between actual information and the design applied, as there is a noticeable trend towards an overtly 'fun seeking' type of displays, where only the user-interface or attraction value is considered at the expense of scientific knowledge. 


\section{References}

[1] M.B. Orams (1994), "Creating effective interpretation for managing interaction between tourists and wildlife", Australian J. of Environmental Education 10: 21-34.

[2] S. Ham and B. Weiler (2001), 100,000 beating bird hearts: tourism, wildlife and interpretation, paper presented at First National Conference on Wildlife Tourism, Australia, 28-30 October 2001.

[3] The International Ecotourism Society (2000), Ecotourism statistical fact sheet, http://www.active-tourism.com/factsEcotourism1.pdf (retrieved 11 October 2013).

[4] G. Moscardo (1998), "Interpretation and sustainable tourism: functions, examples, and principles", The J. of Tourism Studies 9: 2-13.

[5] B.W. Ritchie, N. Carr and C. Cooper (2003), Managing educational tourism, Channel View Publications, Clevedon, England.

[6] J. Parker and R. Ballantyne (2004), "Is educational leisure a contradiction in terms? Exploring the synergy of education and entertainment”, Annals of Leisure Research 7: 54-71.

[7] G. Moscardo, B. Woods and R. Saltzer (2004), "The role of interpretation in wildlife tourism”, in K. Higginbottom ed., Wildlife Tourism: impacts, management and planning, Common Ground Publishing, Australia, pp. 231-251.

[8] http://www.ahi.org.uk/www/about/what_is_interpretation (retrieved 3 October 2013).

[9] F. Tilden (1977), Interpreting Our Heritage, $3^{\text {rd }}$ ed, North Carolina Press, Chapel Hill, U.S.A. .

[10] A. Pierssené (1999), Explaining Our World, E \& FN Spon, London, U.K. .

[11] Y. Edwards (1979), The land speaks: organizing and running an interpretation system, The National and Provincial Parks Association of Canada, Toronto, Canada.

[12] M.B. Orams (1996), "Using interpretation to manage nature-based tourism", J. Sustain. Tour. 4: 81-94.

[13] I.L. Kuo (2002), "The effectiveness of environmental interpretation at resource-sensitive tourism destinations", International J. of Tourism Research 4: 87-101.

[14] M. Girod, C. Rau and A. Schepige (2003), "Appreciating the beauty of science ideas: Teaching for aesthetic understanding", Sci. Educ. 87(4): 574-587.

[15] J. Dewey (1934), Art as experience, Putman's, New York, U.S.A. .

[16] M. Girod and D. Wong (2002), "An aesthetic (Deweyan) perspective on science learning: case studies of three four graders", Elem. School J. 102(3): 199-224.

[17] P. Jackson (1998), John Dewey and the lessons of art, Yale University Press, New Haven, U.S.A. .

[18] K. Pugh (2002), "Teaching for transformative experiences in science: an investigation of the effectiveness of two instructional elements", Teach. Coll. Rec. 104(6) 1101-1137.

[19] K. Pugh and M. Girod (2007), "Science, art, and experience: constructing a science pedagogy from Dewey's aesthetics”, J. of Science Teacher Education 18: 9-27.

[20] M. Greene (1995), Releasing the imagination: essays on education, the arts, and social change, Jossey-Bass, San Francisco, CA, U.S.A. .

[21] K. Pugh, L. Linnenbrink-Garcia and K.L.K. Koskey et al. (2010), "Motivation, learning, and transformative experience: a study of deep engagement in science", Sci. Educ. 94(1): 1-28.

[22] http://publicdomainreview.org/2013/09/19/ernst-haeckels-radiolaria-1862 (retrieved 3 October 2013).

[23] S. Wilson (2010), Art + Science, Thames \& Hudson, London, U.K. .

[24] D. Rothenberg (2012), Survival of the beautiful, Bloomsbury, London, U.K. .

[25] E.O. Wilson (1984), Biophilia, Harvard University Press, Cambridge, U.S.A. . 
[26] J.H. Heerwagen and G.H. Orions (1993), "Humans, habits, and aesthetics", in S.R. Kellert and E.O. Wilson eds., The biophilia hypothesis, Island Press, Washington, U.S.A., pp. 138-172.

[27] S.R. Kellert (1993), "The biological basis for human values of nature", in S.R. Kellert and E.O. Wilson eds., The biophilia hypothesis, Island Press, Washington, U.S.A., pp. 42-72.

[28] H. Rolston (1987), "Beauty and the beast: aesthetic experience of wildlife", in D.J. Decker and G.R. Goff eds., Valuing wildlife: Economic and social perspectives, Westview Press, Boulder, U.S.A., pp. 187-196.

[29] http://www.merriam-webster.com/dictionary/content (retrieved 10 October 2013).

[30] C.E. Shannon and W. Weaver (1949), The mathematical theory of communication, University of Illinois Press, Chicago, U.S.A. .

[31] F.I. Dretske (1981), Knowledge and the flow of information, Basil Blackwell Publisher, Oxford, U.K. .

[32] R.L. Ackoff (1989), "From data to wisdom”, J. of Applied Systems Analysis 16: 3-9.

[33] G.W.F. Hegel (2013) Introductory Lectures on Aesthetics, Digireads, U.S.A. .

[34] R. Eldridge (1985), "Form and content: an aesthetic theory of art", Brit. J. Aesthet. 25: 303-316.

[35] E. Fischer (2010), The necessity of art, Verso, London, U.K. .

[36] D. Rokeby (1997), "The construction of experience: Interface as content”, in C. Dodsworth Jr. ed., Digital illusion: entertaining the future with high technology, ACM Press, New York, U.S.A..

[37] D. Ash (2003), "Dialogic inquiry in life science conversations of family groups in a museum", J. of Research in Science Teaching 40:138-162.

[38] D. Ash (2004), "How families use questions at dioramas: Ideas for exhibit design”, Curator: The Museum Journal 47: 84-10.

[39] C.Sanford, K. Knutson and K. Crowley (2007), ““We always spend time together on Sundays”: how grandparents and their grandchildren think about and use informal learning spaces", Visitor Stud. 10: $136-151$.

[40] J. Heskett (1980), Industrial design, Thames \& Hudson Ltd, London.U.K. .

[41] R. Buchanan (2000), "Wicked problems in design thinking”, in V. Margolin and R. Buchanan eds., The idea of design, MIT Press, Cambridge, U.S.A., pp. 3-11.

[42] R. Ballantyne and K. Hughes (2006), "Using front-end and formative evaluation to design and test persuasive bird feeding warning signs", Tourism Manage. 27: 235-246.

[43] R. Ballantyne, J. Parker, K. Hughes et al. (2007), "Conservation learning in wildlife tourism settings: lessons from research in zoos and aquariums", Environmental Education Research 13: 367-383.

[44] S. Ham and E. Krumpe (1996), "Identifying audiences and messages for nonformal environmental education-a theoretical framework for interpreters", J. of Interpretation Research 1: 11-23.

[45] R. Staiff and R. Bushell (2002), "Interpretation in national parks: some critical questions”, $J$. Sustain. Tour. 10: 97-113.

[46] G. Moscardo (1996), "Mindful visitors: heritage and tourism”, Ann. Tourism Res. 23: 376-397.

[47] R. Wexler (2008), "Onward, Christian penguins: wildlife film and the image of scientific authority", Studies in History and Philosophy of Biological and Biomedical Sciences 39: 273-279.

[48] A.S. Alfonso and J.K. Gilbert (2007), "Educational value of different types of exhibits in an interactive science and technology center", Sci. Educ. 91: 967-987.

[49] P.H. Forestell (1993), "If Leviathan has a face, does Gaia have a soul?: incorportating environmental education in marine eco-tourism programs", Ocean \& Coastal Management 20: 267-282. 
[50] M. Woodward (2005), "Designing the interpretation interface: quality communication design as an aspect of visitor experience in nature based tourism", in proceedings of Imaging Nature: Media, Environment and Tourism Conference, Cradle Mountain, Tasmania, Australia, 27-29 June 2005.

[51] J.M. Montag, M.E. Patterson and W.A. Freimund (2005), "The wolf viewing experience in the Lamar Valley of Yellowstone National Park", Human Dimensions of Wildlife 10: 273-284.

[52] H. Rolston (2002), "From beauty to duty: aesthetics of nature and environmental ethics", in A. Berleant ed., Environment and the arts: perspective on environmental aesthetics, pp. 127-141.

[53] R.T. Paine (1966), "Food web complexity and species diversity", Am. Nat. 100(910): 65-75.

[54] D.L. Cheney and R.M. Seyfarth (1980), "Vocal recognition in free-ranging vervet monkeys", Anim. Behav. 28: 362-367.

[55] A. Thornton and K. McAuliffe (2006), “Teaching in wild meerkats”, Science 313(5784): 227-229.

[56] T. Matsuzawa (2001), Primate foundations of human intelligence: a view of tool use in nonhuman primates and fossil hominids, Springer, Japan.

[57] S. Kim, S. Lappan and J.C. Choe (2011), "Diet and ranging behavior of the endangered Javan gibbon (Hylobates moloch) in a submontane tropical rainforest”, Am. J. Primatol. 73(3): 270-280.

[58] S. Kim, S. Lappan and J.C. Choe (2012), "Responses of Javan gibbon (Hylobates moloch) groups in submontane forest to monthly variation in food availability: evidence for variation on a fine spatial scale", Am. J. Primatol. 74(12): 1154-1167.

[59] A.A. Dayer, H.M. Stinchfield and M.J. Manfredo (2007), "Stories about wildlife: developing an instrument for identifying wildlife value orientations cross-culturally", Human Dimensions of Wildlife 12: 307-315.

\section{Author}

Sanha Kim is a post-doctoral researcher at the Centre for Competitive Creative Design in Cranfield University, U.K., as well as the managing director of the Biodiversity Foundation in Korea. He has a Ph.D. degree on primatology for studying the behavior and ecology of wild gibbons in Indonesia, and is interested in reaching out to the public and engaging people to conservation and environmental issues. E-mail: sanhakim@hotmail.com.

How to CITE: S. Kim, "Delivering the message: a theoretical study on designing science content for nature-based experiences", JCOM 13(03)(2014)A04. 